\title{
A LINGUISTIC APPROACH TO THE EROTISM OF LADY CHATTERLEY'S LOVER
}

\author{
Lorena Pérez Hernández \\ University of La Rioja
}

\begin{abstract}
RESUMEN: Dos son los principales objetivos que se persiguen en las siguientes páginas. En primer lugar, nos proponemos realizar un análisis del lenguaje de la obra que nos ocupa con la intención de aportar algunos argumentos lingüísticos a la línea de crítica literaria que concibe la novela como una obra de carácter erótico, rechazando una visión pornográfica de la misma. En segundo lugar, mediante el análisis detallado del lenguaje de la novela, pretendemos determinar, al menos en parte, las características sintácticas, léxico-semánticas, cognitivas y pragmáticas que definen el lenguaje erótico.
\end{abstract}

ABSTRACT: The present paper pursues two main goals. First, we attempt to carry out a linguistic analysis of Lady Chatterley's Lover in search for some evidence in favour of the line of literary criticism which regards the novel as an erotic rather than as a pornographic work. Second, we take the language of the novel as the starting point for the description of the defining characteristics of the language of erotism. In so doing, we shall pay attention to its syntactic, semantic, pragmatic, and cognitive characteristics.

\section{Introduction}

In A Propos of Lady Chatterley (1981a), D. H. Lawrence draws our attention to one of the main aims pursued in the writing of Lady Chatterley's Lover: He would like to persuade his readers of the necessity of speaking openly and honestly about sex. Unfortunately, the legal repression which affected his novel for over 32 years gave rise to exactly the opposite effect to the one he had desired. His work was censured as pornographic. And throughout those years, secret copies and editions of the novel could be found in most European bookshops and universities, which contributed to make of 'sex' that 'dirty little secret' which, according to Lawrence himself, so dangerously resembles pornography (1981b:57).

As Steven Marcus (1964) states, in his study about sexuality and pornography in Victorian English writers, pornography can be defined as sex without emotion or love. 
Contradictorily enough, there are some passages in Lawrence's novel which seem to echo the above definition:

"What liars poets and everybody were! They made one think one wanted sentiment. When what one supremely wanted was this piercing, consuming, rather awful sensuality." (1986: 258)

Nevertheless, on the whole, the relationship between the two main characters of the novel, Connie and Mellors, is depicted as a much deeper passion. One which can even do without sex and still remain strong:

"But not now, not yet! Now is the time to be chaste, it is so good to be chaste, like a river of cool water in my soul" (1986: 313)

In the present paper, we shall follow this second line of criticism which regards Lady Chatterley's Lover as an erotic rather than a pornographic work, as a novel which approaches the subject of sexual relations between two adults as something natural, as a source of pleasure rather than shame. Furthermore, as a novel which represents the author's struggle to convey his firm conviction that a full sexual relationship cannot be detached from love, feelings, and emotions. In this connection, Alastair Niven (1978) points out how the original title of the novel, Tenderness, clearly reflected Lawrence's intention of underlying the importance of feelings and faithfulness in any human relationship. D.H. Lawrence himself explicitly defines his position towards this issue in one of his letters:

"If there is one thing I don't like it is cheap and promiscuous sex. If there is one thing I insist on it is that sex is a delicate, vulnerable, vital thing that you mustn't fool with. If there is one thing I deplore it is a heartless sex." (in 1973: 203)

Taking into account the above considerations, we attempt to carry out a systematic analysis of the language of the novel. More specifically, it is our goal to contribute with some linguistic evidence to that line of criticism which supports the erotic character of the novel against that which only sees it as a pornographic work. Taking as our starting point Steven Marcus's (1964) description of the characteristics of pornographic prose and language, we shall show that many of those features cannot be attributed to D.H. Lawrence's novel. Moreover, we shall try to prove that those features that can actually be ascribed to it obey to deeply reflected and justified reasons, which have nothing to do with the sheer gratuitous description of a sexual act devoid of feelings. Finally, we shall attempt to characterize the erotic language of the novel by carrying out a systematic analysis that will take into account all levels of linguistic description, from those merely grammatical and lexical, to those higher 
levels which include the former: socio-pragmatic, semantic, cognitive, and discoursive.

\section{Erotic Language vs. Pornographic Language}

"Sex in pornography is sex without the emotions and this we need not discuss any further: D.H. Lawrence has already done the job." (1964:281)

The accusation which Steven Marcus directs to D.H. Lawrence functions as a sententious ending to a brief analysis about the characteristics of pornographic prose which is part of a larger study about sexuality and pornography in Victorian English writers. All or at least some of the features of pornographic language listed in Marcus's essay should be proven to characterize the prose of Lady Chatterley's Lover in order to label the novel as pornographic. However, we shall show that only a few of these features can be found in Lawrence's novel and that, in most cases, they obey to easily justifiable reasons which have nothing to do with pornography. Among them, we find not only Lawrence's wish to 'disinfect' and to recover for everyday language use those taboo words which had acquired an expletive character over the time ('cunt', 'fuck', 'pennis', 'buttocks', etc), but also the need to express, through language, feelings and emotions of ineffable nature, which erotism and pornography share because of their sexual character.

Marcus (1964: 238) explains that one of the characteristics of pornographic prose is the constant use of clichés, formulaic expressions and stereotypes. A careful reading of the erotic passages of Lady Chatterley's Lover reveals the complete absence of such features. Each sentence, each word, each expression have been carefully thought out in order to express the personal, never stereotypical, emotions of Lady Constance. Connie appears as a three-dimensional character. As a woman full of interior conflicts, who goes through a number of pychological stages regarding her relationship with Mellors: an initial stage of emotional isolation, a second stage characterized by her struggles not to let her feelings towards him deprive her of her precious personal freedom, and finally, a last stage represented by her inconditional passion for Mellors. Nothing in the building of this character, from whose point of view the erotic passages of the novel are narrated, can be said to be stereotypical, and nothing in the language that depicts her is found to be formulaic or to follow worn-out clichés. The erotic passages of the novel have been scattered with fragments and sentences in which a skilful use of the free indirect style allows us to approach and even penetrate Connie's feelings and her inner self. There are moments when the expressions which are used to narrate the character's actions or to describe their thoughts appear to be somehow conventional and worn-out (E.g." 'Eh! what it is to touch thee!' he said, as his finger caressed the delicate, warm, secret skin of her waist 
and hips."(p. 131)). But, it is not long before we come across one of those episodes in free indirect style where Connie's peculiar insight into Mellors's feelings or into her own prevents the narration from falling into a stereotypical or easily predictable style:

"That thrust of the buttocks, surely it was a little ridiculous. If you were a woman, and a part in all the business, surely that thrusting of the man's buttocks was supremely ridiculous. Surely the man was intensely ridiculous in this posture and this act" (p. 131).

Another of the features of pornographic language outlined by Marcus (1964: 238) consists in the parallel use of euphemisms and taboo words. On the one hand, D.H. Lawrence consciously avoids euphemisms. His intention, Lady Chatterley's Lover being a good example of it, is to recover those so-called obscene words, so that it will be possible again to speak and think openly about sex. On the other hand, Lawrence certainly uses taboo words. Nevertheless, their use in the novel does not follow from a pornographic aim or a lack of sensibility. On the contrary, it results from a deep and careful reflection on the necessity to abolish, once and for all, the secretism that usually surrounds sex-related issues, given that, in the author's opinion, it is precisely secretism that turns sex into pornography.

In his essay, A Propos of Lady Chatterley (1981a), Lawrence himself acknowledges that the connotations of so-called obscene words must have been somewhat dangerous for people in former more primitive stages of humankind. However, he rushes to point out that in our times, culture and civilization have taught us to distinguish words and thoughts from facts. He adds that, as a result, the use of obscene words ('buttocks', 'fuck', 'cunt'...) with their primitive, referential, nonexpletive meaning, can only help us to clear up our confused feelings and thoughts about sex, and to avoid the fear of our own body.

Unfortunately, as Kenneth Young (1966) has pointed out, words of this kind have acquired such negative connotations and have been used as insults for such a long time that D.H. Lawrence's attempt to recover their primitive meanings for everyday language use was a complete failure.

The third of Marcus's (1964: 238) features of pornographic language refers to the insistent use of adjectives. At first sight, the erotic episodes of Lady Chatterley's Lover seem to reflect this tendency too. Nevertheless, as Marcus is careful to point out, adjectival insistence on its own cannot be taken as a defining feature of pornographic prose, given that any other kind of narrative could easily make use of the same kind of resource to accomplish a completely different goal. Marcus himself states (1964: 238) that the differentiating feature of pornographic prose is not so much the use of a disproportionate number of adjectival modifiers, but the fact that the former are easily interchangeable without a minor change in the meaning of the sentence. In Lady Chatterley's Lover, on the contrary, each adjective has been planned 
to occur in the phrase where it is found and in no other (e.g."(...) she felt his hand groping softly, yet with queer thwarted clumsiness, among her clothing."(p.121); "(...) and she lay there crying in unconscious inarticulate cries" (p. 139)). The adjectival modifiers which can be found in the erotic passages of the novel are not interchangeable and their high degree of appearance obeys to different reasons. As will be shown later, their use allows Lawrence to infuse these passages with a special narrative rhythm. It is a slow rhythm, a sort of slow motion literary camera that, together with other resources of a cognitive nature (metaphors, metonimies, etc.) allows him to communicate, with a considerable degree of success, feelings and emotions whose nature is beyond the expressive potential of language and to which the latter can only point, but very rarely capture in a faithful way.

This seems to be the only point of coincidence between erotic and pornographic language: both attempt to express sensations which are of an ineffable nature, and in this vain attempt, both make use of those cognitive mechanisms mentioned above. Nevertheless, the way in which such cognitive constructs are used in each kind of language differs considerably. The use of metaphors in pornographic language is, according to Marcus, a literal use. His argument is the following:

“(...)its use is unmetaphoric and literal; it seeks to de-elaborate the verbal structure and the distinctions upon which it is built, to move back through language to that part of our minds where all metaphors are literal truths, where everything is possible...”(1964:239)

On the contrary, regarding erotic language, metaphors function in an ordinary way, identifying similar features of two different concepts, mapping our knowledge of concrete everyday entities onto more abstract concepts, and thus, enlarging our understanding of reality. As will be shown below, Lady Chatterley's Lover is a good example of all this.

As I have tried to illustrate so far, only three of the characteristics of pornographic prose listed by Marcus can be attributed to the prose of Lady Chatterley's Lover (adjectival insistence, use of metaphors and use of taboo words), but even these not without some caveats and without clearly stating the different kind of use that Lawrence makes of such resources. The language in Lady Chaterley's Lover is of an erotic rather than a pornographic character. Evidence supporting this statement does not only come from the arguments outlined above, but also from the fact that tenderness, love, and other feelings are always to be found in those episodes which have often been mistakenly censured as pornographic. Feelings permeate these episodes and this can be observed at all levels of linguistic description: from the semantics and the lexicon of the novel ("And closing his hand softly on her upper arm...(p.121); "She adored him till her knees were weak as she walked. (...) she was flowing and alive now and vulnerable, and helpless in adoration of him as the most 
naïve woman." (p.141)), to its syntax, which is never abrupt or sudden, and whose continuous soft flow stresses both the emotional and physical sensations of the characters ("She could only wait, wait and moan in spirit as she felt him withdrawing, withdrawing and contracting, coming to the terrible moment when he would slip out of her and be gone." (p.139)), to the use of metaphors and metonimies, and of other resources linked to sociopragmatics (such as the use of the dialect by Mellors), which emphasize the tenderness that the main characters feel for each other. To all these aspects we shall devote the following section of our paper.

\section{The Erotic Language of Lady Chatterley's Lover}

The study of the language of a literary work cannot be reduced to a mere objective analysis of its linguistic features. The mystery of the style of a novel and of the feelings and reactions that it awakens in the reader is often to be found beyond its narrative or linguistic structure. Nevertheless, we deem it necessary to follow some kind of method in the analysis of the erotic language of Lawrence's novel, at least, as a working instrument that will enable us to carry out our task in a systematic way. Thus, we shall make use of Leech \& Short's work, Style in Fiction (1981), taking advantage of the detailed technique that it offers for the linguistic analysis of prose from a functional perspective. As can be expected, such a method takes into account the three main features that, according to Halliday, every kind of language, including literary language, should fulfil: representative, interpersonal, and textual. The first of these functions includes the lexical, semantic, and cognitive dimensions of language. The second one is concerned with pragmatic and sociolinguistic aspects. Finally, the third one has to do with the syntactic, discoursive, and cohesive characteristics of language. Before we start analysing the above aspects in detail, however, it is necessary to make some brief general remarks about the linguistic features of Lady Chatterley's Lover.

The language of the novel moves back and forth between a realistic and a symbolic key. This feature has already been noted by several authors. Thomas and Huston, for instance, explain:

"Lawrence mixed styles, beginning with realistic scenes and then suddenly shifting to a metaphorical key in which realism is almost completely forsaken." (1973: 198)

It should be noted, however, that such mixture of narrative styles cannot be said to be gratuitous or unconscious. It seems that the reason for the simultaneous use of such opposed narrative styles has to be found in D.H. Lawrence's attitude towards love, erotism and close personal relationships. On the other hand, as has already been 
mentioned above, Lawrence was fully convinced of the need to talk about love and sex without taboos or euphemisms, and ignoring those restrictions imposed by a certain time or by the morality of a certain social class. As a result, he makes use of a prose of a predominantly realistic nature, in which every body organ and every action of the characters is described in a direct way, free from euphemisms or circumlocutions:

"Then with a quiver of exquisite pleasure he touched the warm soft body, and touched her navel for a moment in a kiss. And he had to come in to her at once, to enter the peace on earth of her soft, quiescent body. It was the moment of pure peace for him, the entry into the body of the woman. She lay still, in a kind of sleep (...). The activity, the orgasm was his, all his.” (p.122)

On the other hand, however, as Kenneth Young has pointed out (1966:13), "Lawrence's realism was, indeed, far from the factual and depressing type practised by the young Maugham, Arthur Morrison, or Arnold Bennett, for it was the realism of a poet...". This is due to the fact that together with his desire to free sex from taboos, secretisms, and conventionalisms, Lawrence is also deeply convinced that sex is a great mystery, the mystery of the coming together of two people, of the union of two consciousness in the privacy of a relationship. As a consequence, he believed that, when writing about the mystery of a sensual relationship, we are forced to make explicit what is actually a private, unconscious and mainly ineffable experience in itself. This is the reason why Lawrence makes use of a radically metaphorical and symbolic language in several passages of the novel.

The metaphorical dimension of Lawrence's prose will be dealt with below, in the section devoted to the cognitive mechanisms that permeate the erotic language of the novel. Regarding the symbolic aspects of Lady Chatterley's Lover, these have already been widely studied by a number of critics such as Alastair Niven (1978), Keith Sagow (1981), Kenneth Young (1966), Thomas and Huston (1973), Anthony Beal (1964), and therefore, we choose not to devote any more efforts to this welldocumented fact. Nevertheless, by way of illustration, we could mention Clifford's physical disability as a symbol of his lack of emotions and passion; the symbolic value of the forest where Connie and Mellors meet, which represents a new world, far from the grey and discouraging reality of Tevershall and where feelings and emotions do still exist; Connie's illness as a symbol of her lack of both physical and emotional feelings towards Clifford; and finally, the little chickens, which unmistakably symbolize a new life.

Alastair Niven (1978:183) points out that such a symbolic tendency is not to be found exclusively in Lady Chatterley's Lover, but that, on the contrary, it is a constant feature in all of Lawrence's novels, even though he is mostly unaware of it, as the author himself acknowledges: 
"When I began Lady Chatterley, of course I did not know what I was doingI did not deliberately work symbolically" (letter to D.V. Lederhandler, September, 12th, 1929, in 1978:183)

The understanding of such symbolic instances is, nevertheless, of great relevance for a meaningful reading of Lawrence's novels as has often been stated by the authors listed above.

\subsection{Lexico-semantic Analysis}

Leech and Short (1981) suggest that the lexical and semantic aspects of a text should be studied simultaneously in order to be able to show how the choice of certain words and their frequency of appearance imply certain kinds of meanings. In this section, we will be dealing, therefore, not only with the description and classification of the kind of words that are most frequent in the erotic passages of the novel, their frequency and their placement within the sentence, etc., but also with the type of meaning that they convey, as well as with the description of their role in the modelling of the erotic universe of the novel.

A detailed analysis of the four main erotic passages of Lady Chatterley's Lover (pp. 121-122, 131, 139, 181), yields three relevant lexico-semantic features:

-Firstly, we can observe that, with respect to word classes, nouns and, especially, adjectives outnumber the rest ${ }^{1}$.

-Secondly, we find that even though the amount of concrete and abstract nouns is considerably high, the number of lexical fields to which they belong is extremely small. Moreover, these semantic fields are recurrent in all the erotic passages of the novel. On the one hand, concrete nouns mainly belong to the lexical fields of 'human body' and 'clothes'. We reproduce an illustrative passage of this tendency:

"He laid his hand on her shoulder, and softly, gently, it began to travel down the curve of her back, blindly, with a blind stroking motion, to the curve of her crouching loins. And there his hand softly, softly, stroked the curve of her flank, in the blind instinctive caress." (p.121)

The rare exceptions to this characteristic tendency are due to the use of similes or metaphors which, as should be expected, require the introduction of domains different from those that we wish to compare ("It was like bells rippling up and up to a culmination" (p.139))

1. Nouns amount to about thirty per cent of the words in those passages and adjectives to twenty-one per cent. Verbs and adverbs represent eleven and five per cent of the words respectively. 
On the other hand, abstract nouns belong to the lexical fields of 'erotic and sexual acts', 'states' or 'emotions' (e.g. impulse, orgasms, kiss, nakedness, rhythm, etc.). More specifically, the feelings that are described by means of abstract nouns are of two different types: those related to both physical and sensory 'pleasure' (e.g. beauty, passion, excitation...) and those that express the feelings of 'peacefulness' and 'quietness', both physical and psychological (e.g. drowsiness, peace, silence, etc.)

Finally, exactly the same phenomenon can be observed as regards adjectives. There is a remarkably high number of them, but they all belong to a couple of recurrent lexical fields: the sense of touch (e.g. soft, tender, damp, warm, trembling, etc. ) and those psychological feelings that imply lack of knowledge and the mystery that derives from it (e.g. instinctive, mysterious, unknown, insecure, obscure, secret, strange, hidden, etc. )

The relevance of adjectival modifiers related to tactile sensations, already pointed out by Thomas and Huston (1973), is paralleled by the almost complete absence of adjectives related to the other four senses, especially to the human sense par excellence, the sense of vision. Accordingly, the erotic passages of the novel show a predominance of darkness and mystery, which helps to highlight the sense of touch:

"And there his hand softly, softly, stroked the curve of her flank, in the blind instinctive caress (...); 'You lie there' he said softly, and he shut the door, so that it was dark, quite dark. With a queer obedience, she lay down on the blanket. Then she felt the soft, groping, helplessly desirous hand touching her face softly, softly, with infinite soothing and assurance, and at last there was the soft touch of a kiss on her cheek." (p.121)

The absence of visual perceptions in those passages is perfectly coherent with Lawrence's opinion, already mentioned, that sex and love are great mysteries: the mysteries of two bodies and two consciousness unveiling and getting to know each other in the darkness. In this connection, cognitive linguists such as Lakoff (1987) and Johnson (1987) have shown that our conceptualization of the abstract process of knowledge is based on a metaphoric projection of the concrete and physical action of 'seeing' onto the former abstract domain. To such an extent this is so, that the cognitive metaphor 'to know is to see' has permeated our everyday language in expressions such as 'I see', meaning 'I understand/know'. Taking all this into account, the absence of visual adjectives, whether a conscious choice of the author or not, contributes to emphasize the atmosphere of mystery and lack of mutual knowledge that is so much part of a close erotic relationship between two adults.

Before we move on to our next section, we would like to advance that the adjectival insistence to which we have referred above will be taken up again later when we analyse the syntax of the novel and, especially, the characteristic rhythm of the narrative, to which the former contributes in an important way. 


\subsection{Cognitive Aspects of the Erotic Language of Lady Chatterley's Lover}

When analysing the absence of visual adjectives in the erotic passages of Lady Chatterley's Lover, we made reference to a cognitive mechanism, metaphors, which allowed us to offer a plausible explanation of that fact. It is now our aim to analyse in more depth this and other cognitive constructs which help us to conceptualize such abstract concepts as erotic and sexual impulses, and such complex feelings as love.

Cognitive Linguistics has pinpointed the interrelation that exists between the studies carried out by two different sciences: Cognitive Psychology and Linguistics. The cognitive processes by means of which we are able to conceptualize the world often influence our language. Therefore, the study of the latter appears as a good starting point in the understanding of the former. Literature, as the means by which a writer expresses his particular world vision, must also reflect the workings of our cognitive processes. This is easy to see as regards poetic manifestations, but can also be observed, though to a lesser extent, in prose, and whenever a writer finds herself in the need to express concepts which are beyond our concrete and physical reality.

This is the case of the erotic language of Lady Chatterley's Lover and, most probably, of erotic language as a whole. As Alastair Niven (1978:181) explains, Lawrence requires a type of language that would enable him to express the mystery and sensual depth of feelings such as love and of physical experiences such as orgasms. We agree with Niven that no prose can describe those sensations in a faithful way, given that their essence lies beyond the domain of language. Niven (1978:182) states that in such cases, the writer can only attempt to find an equivalent expression which could point to the sense of the experience that has to be communicated. D.H. Lawrence himself acknowledges that no literature can stand for life itself or penetrate the private tenderness of this kind of experiences (in Niven, 1978: 182). Nevertheless, some cognitive mechanisms such as metaphors or metonimies, together with other syntactic, lexical and rhythmic resources, can make it possible to describe and communicate such experiences, or rather, the sensations and the effects which we assume they bring about in the two main characters of the novel (Mellors and Connie).

Conceptual metaphors are probably the most productive cognitive mechanisms as regards the workings of erotic language. In order to build the erotic atmosphere which characterizes some of the most popular passages of his novel, D.H. Lawrence makes use of several of these metaphors, most of which are already common in our everyday language in western culture. Though they play a significant role in the novel, most of these metaphors appear only sporadically (e.g. 'Love is a war' and 'Orgasms are waves'.) However, one of them is recurrent and it structures most of its erotic passages ('Love/passion is heat').

How can we explain the feeling of love? How can we describe the different stages one goes through when falling in love? This is the problem faced by D.H. Lawrence when the central character of his novel, Connie, who had been introduced 
as an independent liberal woman (p. 6-7), and who, at first, refuses to sacrifice her freedom to love, eventually gives in after a long interior struggle to her love for Mellors. The solution to this problem, whether consciously sought by the author or not, appears to be the use of the conceptual metaphor: 'Love is a war'. Such a metaphor consists of a number of correspondences between the domains of love and war, which allow us to understand the former more abstract one, in terms of the more concrete nature of the latter ${ }^{2}$.

\section{MAPPINGS:}

- LOVERS (before falling in love) ARE WARRIORS

- LOVE IS THE ENEMY

- THE PROCESS OF FALLING IN LOVE IS A WAR/BATTLE

- FALLING IN LOVE IS LOSING THE WAR

- LOVERS (after falling in love) ARE SLAVES

The examples illustrating these mappings in the novel are numerous:

"His body was urgent against her, and she hadn't the heart any more to fight." (p.138); “ 'I got you a key made, my Lady!' he said, saluting, and he offered her the key."; "She knew she had always feared it, for it left her helpless. (...)She must not become a slave. She feared her adoration, yet she would not at once fight against it" (p.141); "WWe are a couple of battered warriors', said Connie. 'Are you battered too?' ', he laughed.” (p.213)3

A similar problem is faced by Lawrence when he attempts to describe the protagonist's orgasms. The only difference being that he is now dealing with a physical rather than an emotional sensation. In order to carry out this task, he makes use of a large number of resources (narrative rhythm, sentence type, adjectival insistence, etc.), among which there is another cognitive metaphor: 'orgasms are waves'. Such a conceptual mapping between the domains of waves and orgasms allows Lawrence to convey the essence of a rather complex sensation, its cyclic nature, its growing initial intensity and its fading away after the climax, like the gradual dissapearing from sight of the wave that has just crashed against the rocks.

In this case the mappings are the following:

2. The conceptual metaphor "love is a war" is so closely related to our conceptualization of love that it is often found in our everyday common language in expressions such as the following: "I cannot fight my feelings for him any more" or "I am a slave of love".

3. Whether it is a mere coincidence or a conscious decision, D.H. Lawrence recurrently refers to Mellors as a soldier: "The man faced lightly round, and saluted with a quick little gesture, a soldier!" (p. 49); “ 'I got you a key made, my Lady!' he said, saluting, and he offered her the key” (p.117). 
- WOMEN ARE SEAS

- MEN ARE DIVERS/PLUNGERS

- THE MOVEMENT OF THE PLUNGER IN THE SEA IS THE MOVEMENT OF A MAN MAKING LOVE

- THE WAVES CAUSED BY THE MOVEMENT OF THE PLUNGER IN THE SEA ARE THE PHYSICAL EFFECTS OF AN ORGASM

By means of these conceptual mappings, Lawrence succeeds in communicating a virtually ineffable sensation in passages of such an evocative nature as the one we include below:

\begin{abstract}
"And it seemed she was like the sea, nothing but dark waves rising and heaving, heaving with a great swell (...) she was ocean rolling its dark, dumb mass. Oh, and far down inside her the deeps parted and rolled asunder, in long, far-travelling billows, and ever, at the quick of her, the depths parted and rolled asunder, from the centre of soft plunging, as the plunger went deeper and deeper, touching lower, and she was deeper and deeper and deeper disclosed, the heavier the billows of her rolled away to some shore, uncovering her, and close and closer plunged the palpable unknown, and further and further rolled the waves of herself away from herself, leaving her, till suddenly, in a soft, shuddering convulsion, the quick of all her plasm was touched, she knew herself touched, the consumation was upon her, and she was gone.” (p. 181)
\end{abstract}

We shall return to the above passage later on, when dealing with the syntax and rhythm of erotic prose. But before we turn to that, one more metaphor remains to be analysed: 'love/passion are heat/fire'. The origin of this metaphor, upon which a great part of the erotic atmosphere of the novel is built, lies in the obvious physical effects brought about by passion and sensuality. This is a very common metaphor both in literary and everyday language (cf. expressions like She is so hot....). In Lady Chatterley's Lover, Lawrence makes a very skilful use of this metaphor by endowing it with a literary dimension which creates a tender poetic effect. The use of this metaphor in the novel is so frequent that we have been forced to select only some of its most interesting instances:

“(...) For suddenly he was aware of the old flame shooting and leaping up in his loins (p.120); "At the back of his loins the fire suddenly darted stronger" (...) "His heart melted suddenly, like a drop of fire..."(p.121);" And his finger-tips touched the two secret openings to her body, time after time, with a soft little brush of fire."(p.232); "I had no warm, flamy life till he gave it me." (p.277) 
It follows logically that the lack of love and passion should be conceptualized as 'coldness' and this is precisely the case in Lawrence's novel, where Clifford is recurrently presented as a 'cold' person:

"What a strange creature, with the sharp, cold inflexible will of some bird, and no warmth, no warmth at all! (p.144)

Together with the metaphors we have presented above, other cognitive mechanisms do also play a role, though certainly a more modest one, in the shaping of the erotic language of the novel. Thus, the fairly frequent use of metonimies, for instance, helps to draw the reader's attention to the most important aspect of the action that is being described. In the passage below, Mellors's hand stands for the gamekeeper himself. This can be seen from the fact that, via a clever use of personification, his hand is attributed several characteristics which are typical of a human being, but not of a body organ.

"Then she felt the soft, groping, helplessly desirous hand touching her body, feeling for her face" (p.121)

\subsection{Syntax, Discourse and Rhythm}

The narrative rhythm of any text derives many of its characteristics from the use the writer makes of syntax and of discourse connectors. Regarding erotic language, there is an even narrower interrelation among these three aspects of a narrative. This is the reason why we have decided to analyse them simultaneously. Our goal is mainly to underline the major role played by narrative rhythm in the creation of an erotic atmosphere. Nevertheless, in order to do so, we shall start by paying attention to the influence of syntax and discourse connectors in the building of narrative rhythm.

The erotic passages of Lady Chatterley's Lover are characterized by a significantly slow rhythm, which has the effect of gradually building up the narrative tension that ends up with an often sudden climax. The syntactic resources that contribute to the creation of this special narrative pace can be summed up as follows. First, there is an accumulation of both subordinate and coordinate complex sentences, and of simple sentences of a considerable length. Second, the former are usually followed by brief simple sentences, often of the exclamative type. The passage which we reproduce below illustrates these aspects:

"She could only wait, wait and moan in spirit as she felt him withdrawing, withdrawing and contracting, coming to the terrible moment when he would slip out of her and be gone. Whilst all her womb was open and soft, and softly clamouring, like a sea-anemone under the tide, clamouring for him to come in 
again and make a fulfilment for her. She clung to him unconscious in passion, and he never quite slipped from her, and she felt the soft bud of him within her stirring, and strange rhythms flushing up into her with a strange rhythmic growing motion, swelling and swelling till it filled all her cleaving consciousness, and then began again the unspeakable motion that was not really motion, but pure deepening whirlpools of sensation swirling deeper and deeper through all her tissue and consciouness, till she was one perfect concentric fluid of feeling, and she lay there crying in unconscious inarticulate cries. The voice out of the uttermost night, the life!" (p.139)

The first two sentences, both of a considerable length, are followed by a third sentence which is disproportionately longer than the one that follows it immediately. This gives rise to an increasing, nearly unsustainable, narrative tension, that leads to the final climax brought about by the brief exclamative final sentence. 4

It is precisely in the building of the narrative tension by means of the piling up of previous information where syntax and discourse connectors play their most important role. To the sentence length and the recurrent use of subordination, coordination and yuxtaposition, we must add a large list of syntactic techniques that contribute to slow down the narrative rhythm and to build up narrative tension:

- frequent use of parenthetical constituents. E.g. "She clung to him, inconscious in passion, and he never quite slipped from her..." (p.139). This kind of sentences often introduces similes. E.g. "Whilst all her womb was open and soft, and softly clamouring, like a sea-anemone under the tide, clamouring for him to come in again and make a fulfilment for her." (p.139)

- high number of direct objects, adjuncts, etc. E.g. "Far down in her she felt a new stirring, a new nakedness emerging." (p.131)

- use of grammatical and lexical constructions, such as parallelisms ("She could only wait, wait and moan in spirit as she felt him withdrawing, withdrawing and contracting, coming to the terrible moment when he would slip out of her and be gone."(p. 139)) or anaphors ("She could do nothing. She could no longer harden and grip for her own satisfaction upon him."(p.139)).

- the recurrent use of repetitions. For example: "Rippling, rippling. rippling (...); “(..) swelling and swelling ...”(p. 139); “(..) and she was deeper and deeper and deeper disclosed...” (p.181)

4. The narrative climax which is represented by the final exclamative sentence has a heavy conceptual weight within the plot of the novel. On the one hand, it signals the instant when the first shared orgasm of the couple takes place and therefore, the moment when their relationship finally attains physical closeness. On the other hand, it also marks the time when Connie finally ends her relationship with Clifford and, as a result, begings to feel herself alive again. Thus, the need to clearly underline this narrative moment. 
- high frequency of appearance of complex phrases, especially nominal and adjectival phrases, whose complexity can be considerable:

a) Nominal Phrases. The vast majority of the nominal phrases that belong to the erotic passages of the novel consist of at least a noun and an adjective. In many cases, their complexity is even higher as can be seen below:

- adjective + adjective + adjective + noun. For instance: “(...) as his finger caressed the delicate, warm, secret skin of her waist and hips" (p.131)

- adjective +noun +noun complement. For example: “ (...) then the magnificent throb of beauty is incomprehensible...” (p.131)

- (noun + adjunct)+noun complement (of+ adjective+adjective+noun), as in "(...)to enter the peace on earth of her soft, quiescent body." (p.122)

- adjective + noun + relative clause. E.g. "(...)and then began again the unspeakable motion that was not really motion." (p. 139)

b) Adjectival Phrases. Their richness, both quantitative and qualitative, contributes to a large extent to slowing down the narrative rhythm. They consist of sequences of two or more adjectives ("(...) with a strange rhythmic growing motion"(p.139)) and are often modified by adverbs (“(...) so that it was dark, quite dark." (p.121))

c) Verb Phrases. Even though their syntax does not appear as a relevant factor in the shaping of the erotic language it is nevertheless important to underline the central role played by the choice of verb tenses in the erotic passages of the novel. In this connection, we observe a high frequency of the use of non-finite verb forms, above all gerunds, within independent clauses:

"Rippling, rippling, rippling, like a flapping overlapping of soft flames, soft as feathers, running to points of brilliance, exquisite, exquisite and melting her all molten inside." (p.139)

The high frequency of appearance of such indefinite forms in those paragraphs immediately preceding a sexual climax of the main characters serves two essential functions. On the one hand, it helps to slow down the narrative rhythm of the passage by highlighting the processual aspect of the action. On the other hand, it allows the author to convey the sensation of atemporality which the characters are assumed to feel during those moments of passion.

The syntactic resources listed aboved contribute to the building up of suspense and growing tension allowing the author to imitate by means of language the climatic feelings of the characters. Likewise, discoursive aspects, such as the abundant use of conjunctions, especially 'and', contribute to the construction of the tense sensual atmosphere of these episodes: 
“(...) and deeper and deeper and deeper disclosed, the heavier the billows of her rolled away to some shore, uncovering her, and closer and closer plunged the palpable unknown, and further and further rolled the waves of herself away from herself...(p.181)

The passage to which this excerpt belongs is one of the best instances of erotic prose in Lady Chatterley's Lover and it displays most of the resources that we have put forward as characteristic of erotic narrative: lexical (high frequency of nouns and adjectives), semantic (small number of recurrent lexical fields), cognitive (conceptual metaphors), syntactic (repetitions, parenthetical phrases, verb tenses, etc.) and discoursive (connectors).

Furthermore, it is also possible to observe in the same passage the functioning of two principles (iconicity and climax) which have been proven to be especially productive regarding erotic prose. Leech and Short (1981) devote a chapter of their book to their description. Erotic language, because of the ineffable nature of the concepts that it attempts to convey, is necessarily a sort of iconic mirror of reality. Such iconicity does not only include onomatopoeic and auditive symbolism, but also the imitation of certain meanings by means of rhythm and syntactic patterns. As can be observed in the passage above, its syntax perfectly mimics the increasing tension that precedes a sexual climax. But this is not enough. In order to achieve this goal, the syntax of the passage must also comply with the second of the principles listed above: the principle of climax. This principle states that the most relevant information should appear at the end of the message. Such a restriction often gives rise to an accumulation of previous information, and it follows logically that the more previous information is accumulated, the more tension and suspense will be added to the narrative. Passages such as the one quoted above constitute perfect evidence supporting the fact that such principles do actually operate in language.

\subsection{Pragmatics and Sociolinguistic Aspects of the Erotic Language of Lady Chatterley's Lover}

To conclude our study of the erotic language of Lady Chatterley's Lover, it is necessary to turn to two aspects which, even though they do not belong to the central study of language, still have to do with our communicative competence and with the social factors that affect its nature (i.e. the use of politeness and the use of the dialect).

At the beginning of the present paper, we emphasized Lawrence's belief in sex and passion as two mysterious aspects of our human existence, which consist in a mutual discovery and a shared knowledge of each other in privacy. This can be further born out by a pragmatic study of the politeness forms in the novel and their relationship to the emotional distance that exists between Connie and Mellors at 
different stages in their relationship. In this sense, it can be observed that the use of polite forms of address is especially frequent at the beginning of their love affair when they are still strangers to each other. Then, there is a period of time during which the use of polite forms of address alternates with the use of more neutral forms. Such an arbitrary alternation mirrors the protagonists increasing emotional and personal closeness. And finally, the success of their relationship and their coming together is signalled by the exclusive use of neutral forms of address. Let us analyse these three phases in more detailed. As corresponds to the times in which the novel is set, the characters address one another by means of polite forms which vary according to the social distance that there is between them. Connie and Mellors's relationship is not an exception to this rule: their first meetings are characterized by the use of polite address forms which signal the social and emotional distance that keeps them apart. For instance: “ 'I got you a key made, my Lady!' he said..." (p.117). Nevertheless, as their relationship evolves and they become closer to each other, we observe a change in their behaviour. Even though they still use polite address forms at the beginning of their conversations ("You've got to remember your Ladyship is carrying on with a game-keeper. (p.130)), they frequently end up using less polite forms that signal the physical closeness that is starting to bind them. (" 'Eh! what it is to touch thee!' he said... (p. 131)). Given that at this stage, Connie has not yet completely abandoned herself to her love for Mellors, and given that Lawrence does not entertain the possibility of a sexual relationship detached from love, it seems logical that the sporadic use of polite distancing address forms is still introduced to mark the emotional distance that still exists between them:

“ 'Goodnight, your Ladyship' his voice (...) She stopped and looked back into the wet dark. She could just see the bulk of him. 'Why did you say that?' she said. 'Nay' he replied. 'Goodnight then, run!' “(

It is not until Connie definitely falls in love with Mellors and becomes aware of her feelings that distancing address forms finally disappear from their conversations (page 180 onwards).

On the other hand, Mellors's use of his native dialect and Connie's attempts to imitate it are likewise linked to the development of their relationship. The dialect in itself is one of the numerous symbols that characterize the novel. The symbol of industrial society, of the proletariat, of Mellors's world, which is just the opposite to the high-brow society represented by Wragby, etc. But, most importantly, it is a symbol of Mellors's sincerity and honesty of what he says when using it.

Yeats admired and praised the use of the dialect in Lady Chatterley's Lover, emphasizing its importance as regards Mellors and Connies's relationship (in Sagow, 1981:195). As he points out, "The coarse language of the one, accepted by both, becomes a forlorn poetry uniting their solitudes, something ancient, humble and 


\section{LORENA PÉREZ HERNÁNDEZ}

terrible." However, it is not like this throughout the novel. At the beginning, Mellors makes use of the dialect to achieve precisely the opposite goal: to make explicit the distance between Connie and himself, and therefore, to mark his territory.

“' 'I mean as 'appen Ah can find anunther pleece as'll du for rearin' th' pheasants. If yer want ter be 'ere, yo'll non want me messin' abaht a' th' time' . She looked at him, getting his meaning through the fog of the dialect." (p.98)

Connie recognizes his intention and is disgusted by his use of the dialect when he is talking to her:

“ 'Why don't you speak ordinary English?' she said coldly. 'Me! Ah thowt it wor ordinary.' She was silent for a few moments in anger." (p.98)

As was the case with the use of address forms, the stronger their relationship becomes, the more the use of the dialect will function as a sign of their union. A good instance of this is Connies's attempt to use the dialect when she finally abandons herself to her feelings for Mellors (e.g. " 'Ay!' she said, imitating the dialect sound" (p.184)). Likewise, when Mellors tries to make it up with Connie after a fight, he uses the dialect (e.g." 'Ma lass!' he murmured. 'Ma little lass! Dunna let's fight! Dunna let's niver fight! I love thee an' th' touch on thee. Dunna argue wi' me!..." (p.216)). Also, those private most intimate moments in their relationship are highlighted by the avoidance of the use of standard English (e.g. " 'Tha's got such a nice tail on thee,' he said, in the throaty caressive dialect." (p. 232).

The use of the dialect becomes a symbol of their union to such an extent that whenever there is trouble in their relationship, such as in the episode in which Connie decides to travel to Venice, Mellors's resentment and discontent is expressed in standard English (e.g. " 'You do as you wish,' he said. And he spoke in good English." (p.233)), thus marking their emotional distancing at that moment.

\section{Final Remarks}

Not all the features of erotic language that we have noted in relation to D.H. Lawrence's novel, Lady Chatterley's Lover, can be taken as characteristic of erotic texts in general. Some of them, such as the use of taboo words with their original meaning or the use of the dialect to emphasize the closeness between the two main character, belong exclusively to Lawrence's literary idiolet. They are not, therefore, relevant when attempting to define erotic language in general. On the contrary, the rest of the characteristics that we have described throughout this paper could certainly constitute the foundations of erotic language. Nevertheless, only a wider and deeper comparative study can confirmed or refute these conclusions. This paper represents just a first approach to the description and characterization of this kind of language. 


\section{References}

BEAL, A. (1964). D.H. Lawrence. London: Oliver and Boyd Ltd.

JOHNSON, M. (1987). The Body in the Mind. Chicago: Chicago University Press.

LAKOFF, G. (1987). Women, Fire, and Dangerous Things: What Categories Reveal about the Mind. Chicago: Chicago University Press.

LAWRENCE, D.H. (1981a). "A Propos de El Amante de Lady Chatterley". In Lawrence, D.H. 1981. Sexo y Literatura. Barcelona: Fontamara.

LAWRENCE, D.H. (1981b). “Pornografía y obscenidad”. In Lawrence, D.H. 1981. Sexo y Literatura. Barcelona: Fontamara.

LAWRENCE, D.H. (1986). Lady Chatterley's Lover. Penguin Books Ltd: Harmondsworth, Middlesex.

LEECH, G. \& SHORT, M. (1981). Style in Fiction. A Linguistic Introduction to English Fictional Prose. London: Longman.

MARCUS, S. (1964). The Other Victorians: A study of Sexuality and Pornography in Mid-Nineteenth-Century England. New York: Besic Books.

NIRVEN, A. (1978). D.H. Lawrence. The Novels. Cambridge: CUP.

SAGOW, K. (1981). The Art of D.H. Lawrence. Cambridge: CUP.

THOMAS \& HUSTON. (1973). Rider's Guide to Great Twentyth Century English Novels. London.

YOUNG, K. (1966). D. H. Lawrence. London: Longmans Green \& CO Ltd. 